\title{
MULTIPLICAÇÃO DE GEMAS AXILARES DE Acacia mearnsii DE WILD. SOB DIFERENTES MEIOS DE CULTURA ${ }^{1}$
}

\author{
Ruter Disarz ${ }^{2}$ e Maísa Pimentel Martins Corder ${ }^{3}$
}

\begin{abstract}
RESUMO - A propagação de indivíduos superiores de acácia-negra (Acacia mearnsii De Wild.) visando ao estabelecimento de florestas mais produtivas, homogêneas, resistentes a pragas e doenças é uma necessidade nos dias atuais. Este estudo objetivou determinar o melhor meio de cultura, a concentração dos seus principais sais e a utilização de carvão ativado para multiplicação in vitro de gemas axilares de A. mearnsii. Plântulas germinadas in vitro forneceram explantes que foram inoculados em diferentes meios de cultura $\mathrm{B}_{5}$, MS, SP e WPM. Foram testadas diversas concentrações do meio MS: 1/4, 1/2, 3/4 e 1/1 (concentração original), 5/4, 3/ $2,7 / 4$ e 2/1, com e sem carvão ativado. Utilizou-se o delineamento de blocos casualizados com cinco, sete e quatro repetições, respectivamente, com quatro explantes por parcela. As avaliações foram feitas em intervalos de 30 dias, através da contagem do número de folhas e gemas e da presença de calos e clorose. Entre os meios utilizados em sua composição original, o MS promoveu a maior multiplicação de gemas (3,7 gemas/explante) aos 30 dias. Entre as concentrações de macronutrientes do meio MS, a diluição para 3/4 da concentração original com a adição de carvão ativado apresentou as melhores respostas para a multiplicação de gemas axilares de acácia-negra (7,7 gemas/explante) aos 60 dias.
\end{abstract}

Palavras-chave: Acácia-negra, carvão ativado e multiplicação.

\section{MULTIPLICATION OF AXILLARY SHOOTS IN Acacia mearnsii DE WILD. UNDER DIFFERENT CULTURE MEDIUM}

\begin{abstract}
The propagation of some superior black wattle individuals (Acacia mearnsii De Wild.) aiming the establishment of more productive, homogeneous forests, resistant to plagues and diseases, is in great need in our days. The objective of the present report is to find the best culture medium and analyze the use of activated charcoal in the in vitro multiplication of axillary buds of A. mearnsii. Explants of in vitro germinated plants were inoculated in different culture media: $\mathrm{B}_{5}$, MS, SP and WPM. Several concentrations of MS medium were tested: $1 / 4 ; 1 / 2 ; 3 / 4 ; 1 / 1$ (original concentration); 5/4;3/2; 7/4 and 2/1, with and without activated charcoal. It was used a randomized experimental design, with five, seven and four replicates, with four explants per replicate. The evaluations were performed after 30 days, through the counting of the numbers of leafs and axillary shoots and the presence of callus and chlorosis. Among the media used in the original composition, the MS promoted the best multiplication of axillary shoots (3,7 buds/explants) on the thirtieth day of culture. Among the MS medium macro-nutrient concentrations, the dilution to 3/4 of the original concentration with the addition of activated carbon promoted the best responses for the multiplication of black wattle axillary shoots ( 7,7 buds/explant) after 60 days of culture.
\end{abstract}

Keywords: Black wattle, activated charcoal and in vitro micropropagation.

\section{INTRODUÇÃO}

Acacia mearnsii (De Wild.), popularmente conhecida como acácia-negra pertence à família Fabaceae, subfamília Mimosoideae, é uma árvore de porte médio, copa arredondada e casca castanho-escura dividida em pequenas placas (MARCHIORI, 1997). É uma espécie fixadora de nitrogênio, que é empregada em regiões subtropicais para proteção e recuperação de solos degradados, produtora de carvão e celulose; utilizada principalmente para a extração de tanino

\footnotetext{
${ }^{1}$ Recebido em 02.09.2007 e aceito para publicação em 29.05.2009.

${ }^{2}$ Programa de Pós-Graduação em Geomática da Universidade Federal de Santa Maria (UFSM). E-mail: <ruterdisarz@ hotmail.com>

${ }^{3}$ Departamento de Ciências Florestais da UFSM. E-mail: <lbfmaisa@ smail.ufsm.br>.
} 
(QUOIRIN et al., 2001; OLD et al., 2002). Sua casca é considerada a principal fonte de tanino do mundo, contendo entre 36 e $41 \%$ de taninos aproveitáveis (JONES et al., 1990), sendo utilizados em diversos setores industriais, de curtumes até a indústria farmacêutica (MONTEIRO et al., 2005). Foi introduzida no Brasil por sementes trazidas da África do Sul (TONIETTO e STEIN, 1997).

Entre as espécies florestais que compõem o cenário silvicultural no país, ocupado tradicionalmente pelos gêneros Eucalyptus e Pinus, A. mearnsii tem assumido, nos últimos anos, relevante expressão comercial ante as relações internas e externas de mercado estabelecidas pelas empresas do setor florestal (PERRANDO e CORDER, 2006). A produção comercial de A. mearnsii ocupa uma área de aproximadamente 160 mil hectares, concentrada no sul do Brasil, da qual participam cerca de 10 mil propriedades da agricultura familiar (FOWLER et al., 1999).

O crescente cultivo de acácia-negra, entretanto, ainda é estabelecido a partir de mudas produzidas por sementes, resultando em florestas com alta variabilidade genética entre os indivíduos do povoamento e, consequentemente, variabilidade na produtividade da floresta. Com o intuito de aumentar a produtividade das florestas de A. mearnsii, a propagação clonal de indivíduos superiores selecionados dentro de um Programa de Melhoramento Genético vem sendo desenvolvida através da cultura de tecidos (BECK et al., 2000; VENGADESAN et al., 2002).

Espécies do gênero Acacia apresentam diversos problemas durante a propagação in vitro. Contudo, sucessos são relatados, principalmente para $A$. several (NANGIAeSINGH, 1996; BECKeDUNLOP, 2001; BECK, 1999). O crescimento in vitro e o desenvolvimento de plantas é determinado por vários fatores, como genótipo, concentração de macronutrientes e micronutrientes no meio de cultura, substâncias orgânicas como reguladores de crescimento, vitaminas e fontes de carbono (PIERIK, 1987). A técnica do cultivo in vitro para de o gênero Acacia tem sua problemática relatada acerca da definição do meio básico a ser utilizado e o balanço adequado entre auxinas e citocininas, principalmente na etapa de multiplicação de gemas.

Este trabalho teve como objetivo estabelecer a melhor formulação e concentração dos principais sais que compõem o meio de cultura utilizado para a micropropagação e clonagem em escala comercial de A. mearnsii.

\section{MATERIAL E MÉTODOS}

Os ensaios foram realizados no Laboratório de Biotecnologia Florestal da Universidade Federal de Santa Maria, Santa Maria, RS. Plântulas de A. mearnsii germinadas in vitro foram utilizadas como fonte de explantes para a instalação dos experimentos. Utilizouse um lote de sementes procedentes de plantios comerciais próximos da cidade de Butiá, RS. A quebra de dormência das sementes foi realizada pela imersão, durante três minutos, em água quente $\left(80^{\circ} \mathrm{C} \pm 2\right)$, seguida de choque térmico em água fria $\left(0^{\circ} \mathrm{C}\right)$ com Tween 20 a $2 \%(\mathrm{v} / \mathrm{v})$, repousando por um período de $24 \mathrm{~h}$. A desinfestação superficial das sementes constitui-se na imersão em álcool $70 \%$ (v/v) durante $40 \mathrm{seg}$, seguida de hipoclorito de sódio a $2,5 \%(\mathrm{v} / \mathrm{v})$ durante $12 \mathrm{~min}$ e em cloreto de mercúrio a $0,2 \%(\mathrm{p} / \mathrm{v})$ por $8 \mathrm{~min}$, sob agitação constante. Posteriormente, as sementes foram enxaguadas com água destilada esterilizada e inoculadas em frascos contendo $30 \mathrm{~mL}$ de meio nutritivo MS, semissolidificado com 6 g.L $L^{-1}$ de ágar.

As plântulas desenvolveram-se durante 21 dias em temperatura de $25 \pm 2{ }^{\circ} \mathrm{C}$ e fotoperíodo de $16 \mathrm{~h}$ e intensidade luminosa de $45 \mu \mathrm{mol} . \mathrm{m}^{-2} \cdot \mathrm{s}^{-1}$. Após esse período, segmentos nodais medindo aproximadamente $1 \mathrm{~cm}$ de comprimento foram inoculados em meio nutritivo com adição de $2 \mathrm{mg} . \mathrm{L}^{-1}$ de BAP (6-benzylaminopurine). Os meios de cultura após o ajuste do $\mathrm{pH}$ para 5,8 foram esterilizados durante $15 \mathrm{~min}$, através de autoclavagem com pressão de 1,5 atm e $125^{\circ} \mathrm{C}$.

As avaliações foram feitas a cada 30 dias de cultivo, quando foram avaliados: presença de calos, presença de clorose e número de gemas, folhas e raízes por explante. Os dados foram transformados em $(\mathrm{X}+0,5)^{1 / 2}$ e submetidos à análise de variância, procedendo-se à comparação entre médias pelo teste de Tukey a 5\% de significância, nos diferentes meios de cultura e ajuste de equações de regressão para a concentração de macronutrientes do meio MS.

\subsection{Análise de diferentes meios nutritivos no desenvolvimento de explantes de acácia-negra}

Foram testados os seguintes meios de cultura: i) MS (MURASHIGE SKOOG, 1962); ii) B $_{5}$ (GAMBORG et al., 1968); iii) WPM (LLOYD e McCROWN, 1981); e iv) SP (BARRUETO-CID e DURZAN, 2003). Os meios de cultura tiveram o seu $\mathrm{pH}$ ajustado para 5,8. A seguir, os meios de cultura foram esterilizados através de 
autoclavagem com pressão de 1,5 atm por um período de $15 \mathrm{~min}$, na temperatura de $125^{\circ} \mathrm{C}$.

O delineamento experimental utilizado foi o de blocos ao acaso, composto por quatro tratamentos constituídos pelos meios de cultura (MS, B $_{5}$, WPM e SP), distribuídos em cinco repetições com quatro explantes por parcela. Para atender às pressuposições do modelo matemático, os valores observados foram transformados pelo método da raiz quadrada. A hipótese de diferença entre os diversos meios de cultura foi testada pela estatística F. O valor do F calculado foi considerado significativo em nível de $\alpha \leq 5 \%$ quando foi superior ou igual ao valor do F tabelado. A comparação entre as médias observadas nos diferentes meios de cultura foi realizada pelo teste de Tukey a $5 \%$ de probabilidade.

\subsection{Influência de diferentes concentrações do meio MS}

Foram testadas as seguintes concentrações de macronutrientes no meio de cultura MS: i) aumento dos macronutrientes em $100 \%$ em relação à concentração original (proporção de 2/1); ii) aumento de macronutrientes em $75 \%$ da concentração original (proporção de 7/4); iii) aumento de macronutrientes em 50\% em relação à concentração original (proporção de $3 / 2$ ); iv) aumento de $25 \%$ dos macronutrientes em relação à formulação original (proporção de 5/4); v) concentração original (1/1); vi) redução dos macronutrientes em $25 \%$ da concentração original (proporção de 3/4); vii) redução de macronutrientes em $50 \%$ em relação à concentração original (proporção de $1 / 2$ ); e viii) redução em $75 \%$ da concentração de macronutrientes em relação à concentração original (proporção de 1/4).

O delineamento experimental utilizado foi o de blocos ao acaso composto por sete tratamentos (diferentes concentrações de macronutrientes em relação à formulação original do meio MS) e uma testemunha (concentração original do meio MS) distribuídos em sete repetições contendo quatro explantes por parcela. Os valores observados foram transformados pelo método da raiz quadrada. Foi realizado o ajuste de equações de regressão das diversas concentrações de macronutrientes no meio MS.

\subsection{Efeito da adição de carvão ativado no meio de cultura}

As diferentes concentrações de macronutrientes no meio de cultura MS e o meio de cultura em sua formulação original descritos no item 2.3 foram testados na ausência e presença de carvão ativado, na concentração de 1 g.L. $\mathrm{L}^{-1}$.

O delineamento experimental utilizado foi em blocos ao acaso em esquema bifatorial ( $8 \times 2)$, composto por sete tratamentos (diferentes concentrações de macronutrientes em relação à formulação original do meio MS) e uma testemunha (concentração original do meio MS) testados na ausência e na presença de carvão ativado, distribuídos com quatro repetições contendo quatro explantes por parcela. As avaliações foram conduzidas de acordo com o descrito nos itens anteriores. Os valores observados foram transformados pelo método da raiz quadrada, sendo realizado o ajuste de equações de regressão das diversas concentrações de macronutrientes no meio MS testadas na presença e ausência de carvão ativado.

\subsection{Aclimatação das plantas}

Após o período de enraizamento, as plântulas foram retiradas dos frascos e as raízes, lavadas em água corrente para a remoção do excesso de meio de cultura. Em seguida, as plântulas foram acondicionadas em frascos de cultura (Figura 1MP) contendo substrato orgânico esterilizado Plantmax ${ }^{\circledR}$ e vermiculita $(1: 1)$. Os frascos de cultura contendo as plântulas foram mantidos fechados em sala de incubação, sob condições controladas descritas anteriormente por 28 dias. As tampas dos frascos de cultura foram parcialmente abertas aos sete dias e totalmente abertas aos 14 dias. Após o período na sala de incubação, as plântulas foram transferidas para tubetes de $280 \mathrm{~cm}^{3}$ e levadas para a casa de vegetação.

\section{RESULTADOS E DISCUSSÃO}

\subsection{Efeito dos diferentes meios de cultura}

Os quatro meios de cultura testados (MS, B 5 , WPM e SP) promoveram a multiplicação de gemas axilares de $A$. mearnsii. Foi observada diferença significativa entre os meios de cultura analisados, de acordo com a estatística $\mathrm{F}$, a $5 \%$ de probabilidade de erro (Tabela 1). Alguns resultados similares foram encontrados em algumas espécies do gênero Acacia. Em Acacia mangium, foi observada a formação de duas a cinco gemas por explante ao ser utilizado o meio de cultura MS como fonte nutritiva (BHASKAR et al., 1996). Em outros estudos realizados com espécies do gênero Acacia, como A. sclerospema, A. sinuata, $A$. mangium, A. catechu, A. albida, inclusive A. mearnsii,

R. Árvore, Viçosa-MG, v.33, n.4, p.599-606, 2009 
foram observados melhores índices de multiplicação das gemas axilares com o meio nutritivo MS. Resultados satisfatórios também foram relatados para a multiplicação in vitro de espécies de acácias com outros meios de cultura (DRIVER e KUNIYUKI, 1984; DEWAN et al., 1992; MONTEUUIS et al., 1998; BECK e DUNLOP, 2001; VENGADESAN et al., 2002).

O número médio de gemas por explante observada em plântulas de acácia-negra (Tabela 1) desenvolvidas no meio de cultura $B_{5}$ foi semelhante ao verificado por Borges et al. (2004). Nesse estudo, os autores utilizaram a mesma concentração de BAP ( $\left.2 \mathrm{mg} . \mathrm{L}^{-1}\right)$ no meio nutritivo, o que evidenciou a superioridade do meio MS na multiplicação de gemas axilares de $A$. mearnsii. Foi observada a formação de calos em praticamente todos os explantes. Não foi verificada diferença significativa entre os tratamentos dessa variável. Foi observada a incidência de clorose em todos os tratamentos analisados, embora exista evidência de ausência de correlação com os tratamentos empregados, efeito relatado nos estudos realizados por Quoirin et al. (2001) e Perrando (2003). Não foi observada a formação de raízes nos explantes.

As médias superiores observadas no meio de cultura MS neste estudo podem estar associadas ao fato de esse meio nutritivo possuir maior força iônica em relação aos demais tratamentos testados. A concentração total de nitrogênio observada nas formulações dos meios de cultura testados (MS: $60 \mu \mathrm{M} ; \mathrm{B}_{5}: 27 \mu \mathrm{M}$; WPM: $15 \mu \mathrm{M}$; e SP: $30 \mu \mathrm{M}$ ) tem reforçado essa hipótese. O sucesso na utilização dos demais meios de cultura provavelmente encontra-se associado a um período de subcultivo menor (ROCHA et al., 2007).

Tabela 1 - Número médio de gemas axilares e de folhas por explante de Acacia mearnsii De Wild., em diferentes meios nutritivos, aos 30 dias de cultivo

Table 1 - Number of Acacia mearnsii De Wild. axillary shoots and leaves, after 30 days of culture in different culture media

\begin{tabular}{lcc}
\hline Meios nutritivos & $\begin{array}{c}\text { Número médio } \\
\text { de gemas/explante }\end{array}$ & $\begin{array}{c}\text { Número médio } \\
\text { de folhas/explante }\end{array}$ \\
\hline MS & $3,66 \pm 0,16 \mathrm{a}$ & $5,30 \pm 0,29 \mathrm{a}^{1}$ \\
WPM & $3,06 \pm 0,17 \mathrm{~b}$ & $4,52 \pm 0,38 \mathrm{~b}$ \\
B5 & $2,89 \pm 0,29 \mathrm{bc}$ & $4,54 \pm 0,24 \mathrm{~b}$ \\
SP & $1,28 \pm 0,29 \mathrm{c}$ & $3,26 \pm 0,47 \mathrm{c}$ \\
\hline
\end{tabular}

${ }^{1}$ Médias seguidas por letras diferentes diferem entre si pelo teste de Tukey a $5 \%$ de probabilidade de erro.

R. Árvore, Viçosa-MG, v.33, n.4, p.599-606, 2009

\subsection{Efeito da concentração de macronutrientes do meio MS com e sem adição de carvão ativado}

A elevação na concentração dos macronutrientes conduziu à senescência e morte dos tecidos conforme a Figura 1 (D-F). Entretanto, a redução de $25 \%$ na concentração dos principais sais do meio MS mostrouse mais eficaz para a formação de gemas e folhas (Figura 2), embora tenham sido evidenciados efeitos prejudiciais ao desenvolvimento de folhas e de gemas com a redução de $50 \%$ e $75 \%$ na concentração dos sais. A utilização de baixas concentrações de macronutrientes no meio de cultura MS favoreceu o aparecimento de sintomas de deficiência nutricional como raquitismo e necrose foliar. Outros estudos foram bem-sucedidos na multiplicação e enraizamento de plântulas das espécies Acacia bivenova e $A$. sclerospermaao com a utilização do meio nutritivo MS contendo uma concentração reduzida dos principais sais (AHÈE e DUHOUX, 1994; AHUJA, 1993). Foram observadas multiplicação de gemas superior, uma maior área foliar, uma menor formação de calos, uma maior formação de raízes e ausência de clorose em explantes subcultivados em meio MS com a adição de carvão ativado. Uma hipótese para esse comportamento foi o maior efeito da adsorção de substâncias inibidoras de crescimento, como os polifenóis e o etileno, o que já foi relatado por Pan e Staden (1998).

A análise de regressão da concentração de macronutrientes apresentou resposta quadrática negativa (Figura 2). A redução de $25 \%$ dos principais sais do meio MS com ou sem a adição de carvão ativado ao meio de cultura resultou em 7,2 gemas/explante (Figura 2A) e 7,7 folhas/explante (Figura 2C) aos 60 dias.

Com a presença de carvão ativado no meio de cultura, os índices de clorose e de presença de calos foram significativamente menores; e sintomas como o raquitismo e a necrose foliar não ocorreram. Efeitos similares foram também observados por Quoirin et al. (2001). A presença de carvão ativado proporcionou a formação de raízes nos demais explantes (Figura 1CI) Quando a concentração de macronutrientes foi dobrada, a incidência de calos foi menor, no entanto aos 60 dias os explantes estavam em avançado processo de senescência com a perda de praticamente todas as folhas formadas (Figura 1DE). 


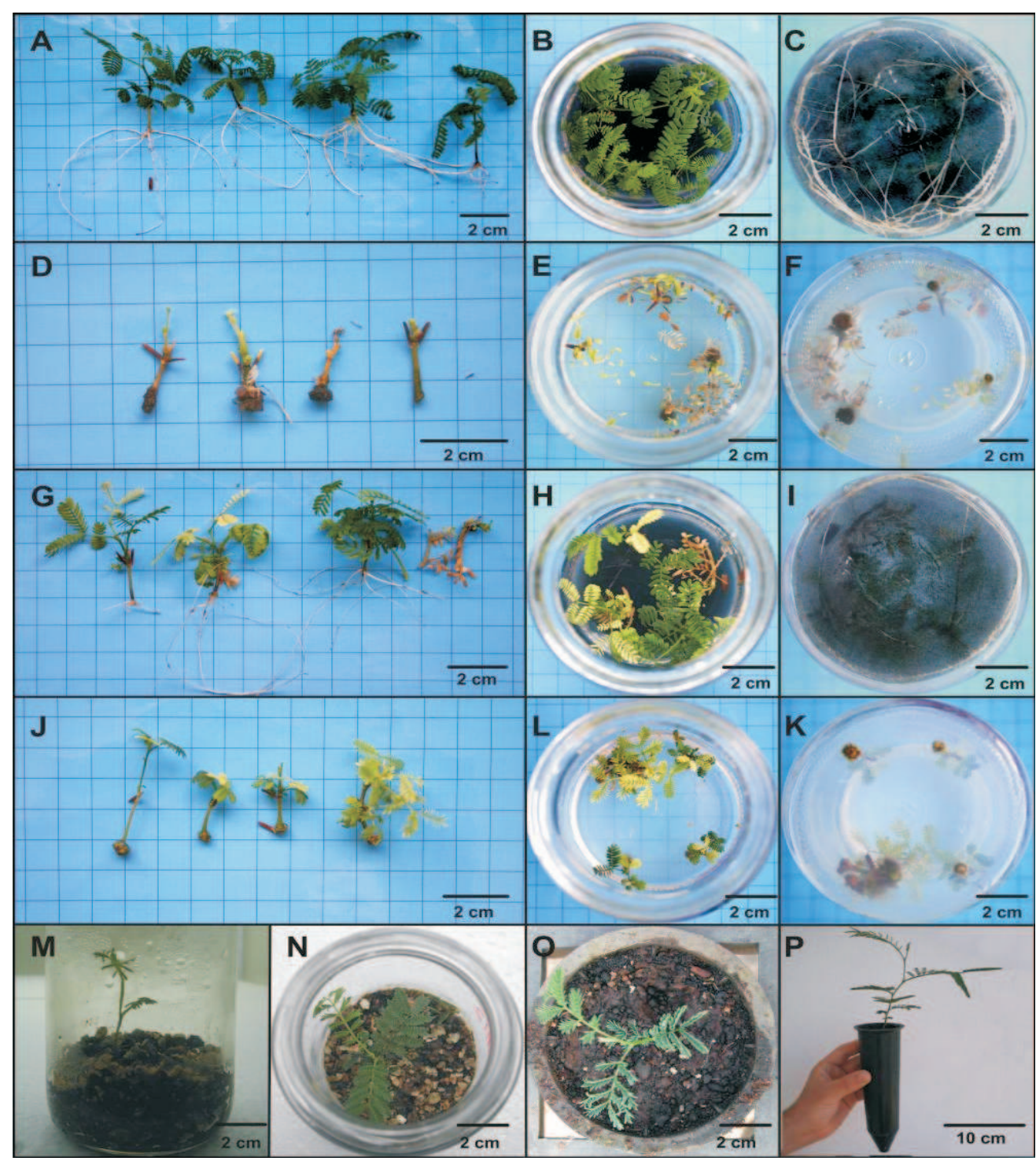

Figura 1 - Regeneração in vitro de gemas axilares de A. mearnsii a partir de segmentos de hipocótilos cultivados em meio MS, aos 60 dias. (A), (B) e (C): desenvolvimento dos explantes sob a redução de $25 \%$ da concentração de macronutrientes do meio MS com adição de carvão ativado $\left(1 \mathrm{mg}^{\left.-\mathrm{L}^{-1}\right)}\right.$; (D), (E) e (F): desenvolvimento dos explantes sob o aumento de $100 \%$ na concentração de macronutrientes do meio MS sem a adição de carvão ativado; $(\mathrm{G})$, (H) e (I): desenvolvimento dos explantes sob o aumento de $100 \%$ na concentração de macronutrientes do meio MS com a adição de carvão ativado $\left(1 \mathrm{mg} . \mathrm{L}^{-1}\right)$; (J), (K) e (L): desenvolvimento dos explantes sob a concentração original de macronutrientes do meio MS sem a adição de carvão ativado; e (M), (N), (O) e (P): aclimatação das plantas em sala de incubação e casa de vegetação, respectivamente.

Figure 1 - In vitro axillary shoots of A. mearnsii from segmented hypocotyls after 60 days of cultivation in MS medium. $(A),(B)$ and $(C)$ Development of the explants submitted to the reduction of $25 \%$ of all macronutrients of the $M S$ medium with the addition of activated charcoal $\left(1 \mathrm{mg} . \mathrm{L}^{-1}\right) ;(D),(E)$ and $(F)$ Development of the explants in MS medium with the double concentration of macronutrients, without addition of activated charcoal; $(G)$, (H) and (I) Development of the explants in MS medium with the double concentration of macronutrients, with addition of activated charcoal $\left(1 \mathrm{mg} . L^{-1}\right) ;(J),(K)$ and $(L)$ Development of the explants in the original MS medium without addition of activated charcoal, and $(M),(N),(O) e(P)$ Acclimatization of plants in the incubation room and in the green house, respectively. 

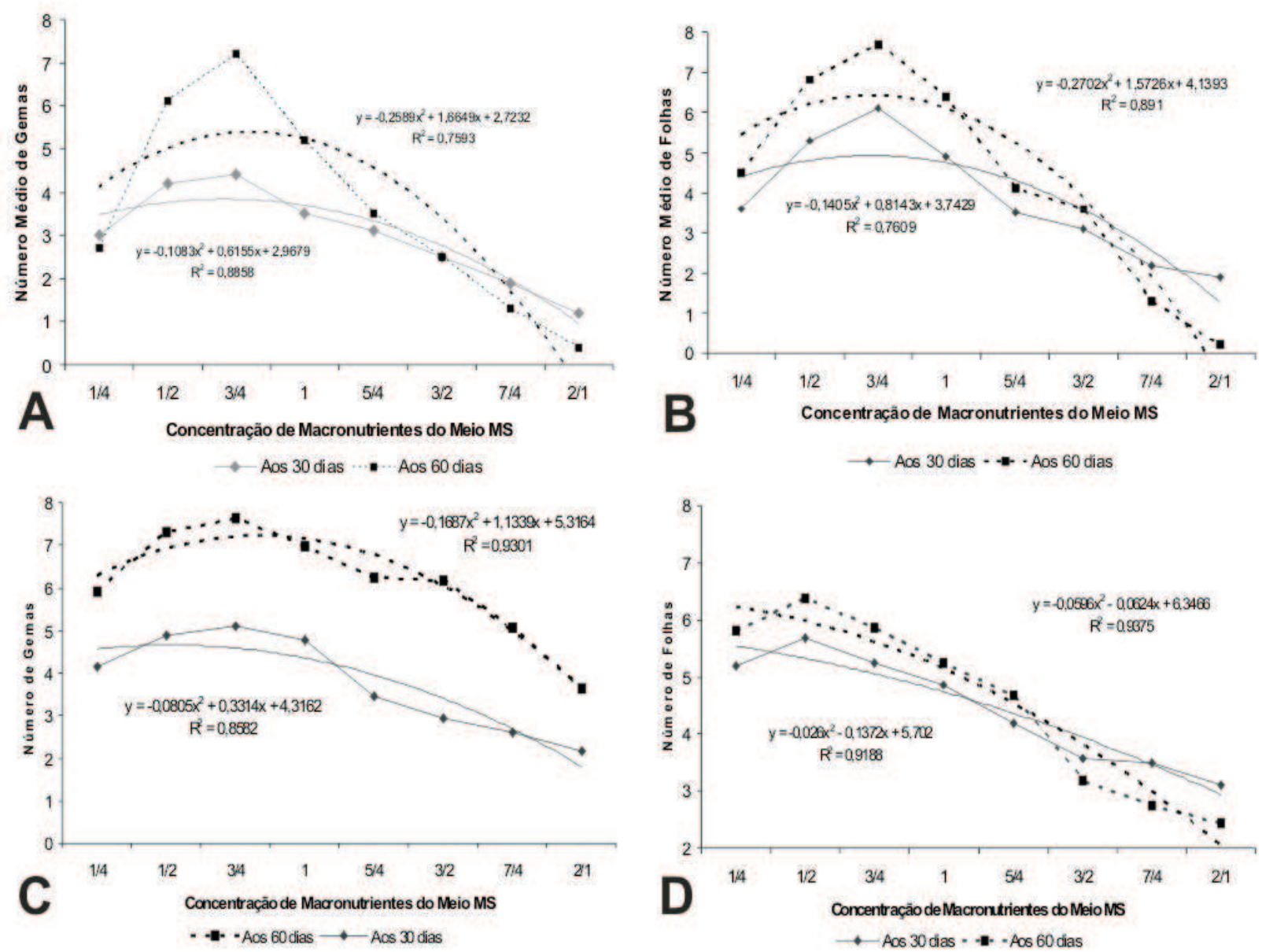

Figura 2 - Estimativas do número médio de gemas axilares e folhas por explante de Acacia mearnsii De Wild., em função das concentrações de macronutrientes do meio MS: A) número médio de gemas em meio sem carvão ativado; B) número médio de folhas em meio sem carvão ativado; C) número médio de gemas em meio com carvão ativado; e D) número médio de folhas em meio com carvão ativado.

Figure 2 - Estimatives of the mean number of Acacia mearnsii De Wild. axillary shoots and leaves per explant, according to the concentration of MS medium macronutrients: A) Mean number of axillary shoots in medium without activated charcoal; B) Mean number of leaves in medium without activated charcoal; C) Mean number of axillary shoots in medium with activated charcoal; D) Mean number of leaves in medium with activated charcoal.

Mesmo com a ausência de auxinas, a adição de carvão ativado ao meio de cultura impede a incidência de luz na base do explante, estimulando o enraizamento dos explantes (PAN e van STADEN, 1998). Neste estudo, foi observado o enraizamento de $92 \%$ dos explantes cultivados em meio MS com 3/4 da concentração de macronutrientes com a adição do carvão ativado.

Resultados similares foram obtidos por Huang et al. (1994), que utilizaram a composição original do meio MS e encontraram 2,4 gemas/explante, enquanto Quoirin et al. (2001) com a redução para 3/4 da concentração original de macronutrientes do meio MS encontraram três gemas/explante.

Mounteuuis et al. (1998), trabalhando com diferentes concentrações de macronutrientes, salientaram a relação da composição dos principais sais constituintes do meio nutricional com a morfogênese in vitro. Al Wassel (2000) relatou que o meio MS (concentração original de sais) promoveu a maior multiplicação de A. seyal, porém apresentou formação de raízes anormais quando comparado com o tratamento utilizando MS com metade da concentração original de sais. 
Os explantes mantidos em meio MS com a redução de $25 \%$ na concentração dos macronutrientes foram mantidos em multiplicação até o $11^{\circ}$ subcultivo. Após, foram enraizados sem a adição de auxinas e aclimatados com 98\% de sobrevivência das plantas (Figura 2P).

\section{CONCLUSÕES}

Este trabalho permitiu a micropropagação in vitro de A. mearnsii. No entanto, a etapa de multiplicação precisa ser otimizada.

Entre os meios de cultura testados ( $\mathrm{B}_{5}, \mathrm{MS}, \mathrm{SP}$ e WPM), o MS promoveu a maior formação de gemas e folhas em explantes de $A$. mearnsii. A redução de $25 \%$ na concentração dos macronutrientes do meio MS combinado com a adição de 1 g.L $L^{-1}$ de carvão ativado promoveu as maiores taxas de multiplicação e possibilitou o enraizamento e aclimatação da espécie.

\section{AGRADECIMENTOS}

À Empresa Agroseta S.A., pelo apoio financeiro e fornecimento de sementes.

\section{REFERÊNCIAS}

AHÈE, J.; DUHOUX, E. Root culturing of Faidherbia = Acacia albida as a source of explants for shoot regeneration. Plant Cell, Tissue and Organ Culture, v.36, n.2, p.219-225, 1994.

AHUJA, R. M. Microprogation of woody plants. Dordrecht: Kluwer Academic Puplisher, Forestry sciences, 1993. v.41.

Al-WASSEL, A. Micropropagation of Acacia seyal Del. in vitro. Journal of Arid Environments, v.46, n.4, p.425-431, 2000.

BARRUETO-CID, L. P.; DURZAN, D. J. Efeito da cefotaxima na germinação, crescimento e brotação de gemas axilares, sob condições in vitro. Brasília: Embrapa Recursos Genéticos e Biotecnologia, Embrapa Recursos Genéticos e Biotecnologia, 2003. 35p. (Boletim de Pesquisa e

Desenvolvimento, 49).

BECK, S. L. Micropropagation of Acacia mearnsii De Wild. 1999. 126f. Tese University of Natal, Pietermaritzburg, 1999.
BECK, S. L.; DUNLOP, R. Micropropagation of the Acacia species - a review. In vitro Cellular Development Biological Plant, v.37, n.55, p.531-538, 2001.

BECK, S. L.; DUNLOP, R.; van STADEN, J. Rejuvenation and micropropagation of Acacia mearnsii De Wild. Using coppice material. Plant Growth Regulation, v.26, n.1, p.149-153, 1998.

BECK, S. L.; DUNLOP, R.; van STADEN, J. Meristem culture of Acacia mearnsii. Plant Growth Regulation, v.32, n.1, p.49-58, 2000.

BHASKAR, P.; VERMA, B.; KANT, U.

Micropropagation of Acacia mangium De Wild. Through nodal bud culture. Indian Journal of Experimental Biology, v. 34, n.6, p.590-591, 1996.

BORGES, N. J.; SOBROSA, R. C.; CORDER, M. P. M. Multiplicação in vitro de gemas axilares de Acácia-negra (Acacia mearnsii De Wild.).

Revista Árvore, v.28, n.4, p.493-498, 2004.

DEWAN, A.; NANDA, K.; GUPTA, S. C. In vitro micropropagation of Acacia nilotica Subsp. India Brenan via cotyledoary nodes, Plant Cell Repórter, v.12, p.18-21, 1992.

DRIVER, J. A.; KUNIYUKI, A. H. In vitro propagation of paradox walnut root stocks. HorticScience, v. 19, p.507-509, 1984.

FOWLER, J. A. P. et al. Germinação e vigor de sementes de Acacia mearnsii De Wild. coletadas em diferentes povoamentos do Estado do Rio Grande do Sul. Colombo: Embrapa-CNPF, 1999. 4p. (Comunicado Técnico, 39).

OLD, K. M. et al. FAO/IPGRI Technical Guidelines for the Safe Movement of Germplasm. No. 20. Acacia spp. Rome: Food and Agriculture Organization of the United Nations, Rome/International Plant Genetic Resources Institute, 2002.

GAMBORG, O. L.; MILLER, R. A.; OJIMA, K. Nutrient requirements of suspension cultures of soyabean root cells. Experimental Cell Research, v.50, n.1, p.151-158, 1968.

R. Árvore, Viçosa-MG, v.33, n.4, p.599-606, 2009 
HUANG, F. H.; Al-KHAYRI, J. M.; EDWARD, E. Micropropagation of Acacia mearnsii. In Vitro Cellular \& Developmental BiologyPlant, v.30, n.1, p.70-74, 1994.

JONES, T. C.; BATCHELOR, C. A.; HARRIS, P. J. C. In vitro culture and propagation of Acacia species ( $A$. bivenova, A. holosericea, A. salicina, A. saligna and A. sclerosperma),

International Tree Crops Journal, v.6, n.1, p.183-192, 1990.

LLOYD, G.; McCROWN, B. Commercially-feasible micropropagation of mountain laurel, Kalmia latifoila by use of shoot-tip culture. Proceedings-

International Plant Propagators Society, v.30, p.421-427, 1981.

\section{MARCHIORI, J. N. C. Dendrologia das} angiospermas: leguminosas. Santa Maria: Universidade Federal de Santa Maria, 1997. 200p.

MONTEIRO, J. M.; ALBUQUERQUE, U. P.; ARAÚJO, E. L. Taninos: uma abordagem da química à ecologia. Química Nova, v.28, n.5, p.892-896, 2005.

MOUNTEUUIS, W.; BON, M. C. Influence of auxin and darkness on in vitro rooting of micropropagated shoots from mature and juvenile Acacia mangium. Plant Cell, Tissue and Organ Culture, v.63, n.3, p.173-177, 2000.

MURASHIGE, T.; SKOOG, F. A revised medium for rapid growth and bioassays with tobacco tissue cultures. Physiologia Plantarum, v. 15, n.3, p.473-497, 1962.
NANGIA, S.; SINGH, R. Micropropagation of Acacia tortilis hayne (Umbrella thorn) through cotyledonary node culture. Indian Journal of Plant Physiology, v.1, n.2, p. 77-79, 1996.

PAN, M. J.; van STADEN, J. The use of charcoal in in vitro culture - A review. Plant Growth Regulation, v.26, n.3, p.155-163, 1998.

PERRANDO, E. R. Propagação vegetativa de acácia-negra (Acacia mearnsii De Wild.). 2003. 123f. Dissertação (Mestrado em Ciências Florestais) - Universidade Federal de Santa Maria, Santa Maria, 2003.

PERRANDO, E. R.; CORDER, M. P. M. Rebrota de cepas de Acacia mearnsii em diferentes idades, épocas do ano e alturas de corte. Pesquisa Agropecuária Brasileira, v.41, n.4, p.555-562, 2006.

PIERIK, R. L. M. In vitro culture of higher plants. Boston: Martinus Nijhoff, 1987. 344p.

QUOIRIN, M. et al. Multiplication of juvenile black wattle by microcuttings. Plant Cell, Tissue and Organ Culture, v.66, n.3, p.199-205, 2001.

ROCHA, S. C. et al. Micropropagação de Cabralea canjerana. Revista Árvore, v.31, n.1, p.43-50, 2007.

TONIETTO, L.; STEIN, P. P. Silvicultura da acácianegra (Acacia mearnsii DE Wild.) no Brasil. Florestal Estatístico, v.4, n.12, p.11-16, 1997.

VENGADESAN, G. et al. In vitro propagation of Acacia species - A review. Plant Science. v.163, n.4, p.663-671, 2002. 